\title{
Correspondence
}

\section{Difficult Glaucomas}

Sir, I would like to draw your attention to serious inaccuracies and shortcomings in a recent article in your Journal entitled, 'How to Manage the Unresponsive Patient', by R. A. Hitchings and J. Lattimer. ${ }^{1}$

In this article, reference is made to my research and practice in the management of severe glaucoma. I would like here to correct several erroneous statements and misquotations from my work.

1. 'Molteno feels the young patient does not scar as extensively as the elderly.' This is not true. I have indeed shown age to be a factor in bleb fibrosis, however, the pattern is one of limited fibrosis in young infants age $0-18$ months, severe bleb fibrosis between 18 months and around 55 years, and progressively less marked fibrosis with increasing age beyond 55 years. In general therefore, contrary to the statement made by these authors, the young, apart from infants, scar more intensively than the elderly.

2. Referring to my anti-fibrotic regime, the authors state that, 'I limit its use to the fit patient'. This is incorrect. In my practice, fibrosis suppression medication is used to control bleb fibrosis in a dosage which depends on (a) the physiological age of the patient, (b) the severity of the glaucoma and (c) the circumstances of the case. In general, young infants (under 18 months of age) and the elderly require little or no fibrosis suppression medication while those in the age range 18 months to 55 years would be given dosage in proportion to the severity of the glaucoma.

3. The result and misleadingly short follow up reported in this paper (but not cited) reflects the results obtained in a limited trial undertaken to determine the influence of bleb area on the performance of implants which was reported in the Trans- actions of the Ophthalmological Society of New Zealand in $1981 .^{2}$ Earlier and later papers printed in the New Zealand Transactions $^{3.4}$ and a paper more readily available in the AMA Archives of Ophthalmology in January 1984 contain results of follow up over 300 cases of implants going back to the year 1969 and showed that this procedure, far from being a surgical gimmick, has stood the test of time.

4. The use of these implants in human cases was first reported in 1969. Subsequent work showed that it was possible, by controlling bleb fibrosis, to obtain good results in all types of secondary glaucoma.

None of the extensive body of literature is cited by the authors who selectively and incorrectly report my work. I believe this is lax scholarship by international standards of scientific reporting.

To correct this oversight, I would suggest that readers interested in a concise and comprehensive account of the state of the art as regards glaucoma implants should refer to the chapters 10 and 42 in 'Glaucoma' edited by $\mathrm{J}$. E. Cairns published by Grune and Stratton, which contains a comprehensive list of references bearing on this subject. ${ }^{6,7}$

Department of

A. C. B. Molteno

Ophthalmology

University of Otago

Dunedin

New Zealand

\section{References}

${ }^{1}$ Hitchings RA and Lattimer J: How to manage the unresponsive patient. Eye 1987, 1: 55-60.

${ }^{2}$ Molteno ACB: The optimum design of drainage implants for glaucoma. Trans Ophthalmol Soc NZ 1981, 33: 39-41.

${ }^{3}$ Molteno ACB: Mechanisms of intraocular inflammation. Trans Ophthalmol Soc NZ 1981, 32: 69-72. 
${ }^{4}$ Molteno ACB: The use of draining implants in resistant cases of glaucoma. Late results of 110 operations. Trans Ophthalmol Soc NZ 1983, 35: 94-97.

${ }^{5}$ Molteno ACB, Ancker E, Bartholomew RS: Surgical technique for advanced juvenile glaucoma. Arch Ophthalmol 1984, 102: 51-57.

${ }^{6}$ Molteno ACB: Use of Molteno implants to treat secondary glaucoma. Glaucoma ed. JE Cairns, pub. Grune and Stratton. 1986; Vol 1, Ch 10; 211-238.

${ }^{7}$ Molteno ACB: Neovascular glaucoma-diagnosis and therapy. Glaucoma ed. JE Cairns, pub. Grune and Stratton. Vol 1, Ch 42; 883-915.

Sir, Dr Molteno has justly won international fame with his success in the management of 'Difficult Glaucomas'. Any contribution from him in this field is, therefore, to be welcomed. In his letter, he discussed a number of points made in our article. ${ }^{1} \mathrm{He}$ is concerned that his 'plate and tube' device is not seen as a 'surgical gimmick', but as a device that has 'stood the test of time'. His reported successes with his device and the length of his follow-up show that. When we reported the surgical results with the modified 'tube and gutter' device we had to compare the results with other silicone drainage objects and Dr Molteno's was clearly the one we should choose. We consider that the tube and gutter device was an alternative and perhaps cheaper method of treating these types of glaucoma. In making a comparison, we considered two aspects. The first of these was the question of Dr Molteno's antifibrosis regime and the second was the surface area required for aqueous absorption.

Concerning the first point, Dr Molteno states in his letter that he administers his antifibrosis regime according to 'the circumstances of the case'. In an independent report, ${ }^{2}$ the authors noted that 'the antifibrosis regime gave an unacceptably high fre- quency of side effects in a large number of patients, some of whom had to have their therapy terminated. The antifibrosis regime was eventually used only on fit young patients'. (It should be borne in mind that the development of antifibrotic agents given locally is one of the most exciting areas of glaucoma research today. It is to be hoped that an antifibrotic agent developed from 5-Flourouracil will be the treatment of choice in the management of this type of glaucoma in the future).

Concerning the second point, because of our concern with the systemic antifibrotic regime, especially in the young glaucoma patient, we looked at methods of increasing the area of the drainage bleb. By this increase we hoped to avoid the problem of fibrosis developing around the drainage site by increasing the area available for aqueous absorption. We consider that, even if the fibrosis reduced flow per unit area, a massive increase in the area of absorption would still allow normal intraocular pressures to be maintained. Our results demonstrate that this approach met with some success.

Dr Molteno has drawn our attention to the fact that we quoted him but failed to cite him. For pointing out this omission we are grateful and give the reference below. ${ }^{3}$

\section{Moorfields Eye Hospital R. A. Hitchings High Holborn \\ London WC1V 7AN}

\section{References}

${ }^{1}$ Hitchings RA and Lattimer $\mathrm{J}$ : How to Manage the Unresponsive patient. Eye 1987, 1: 55-60.

${ }^{2}$ Brown RD and Cairns JE: Experience with the Molteno Long Tube Implant. Trans Ophthalmol Soc UK 1983, 103: 297-313.

${ }^{3}$ Molteno ACB: The Optimal Design of Drainage Implants for Glaucoma. Trans Ophthalmol Soc NZ 1981, 33: 39-41. 